\title{
Rapid modification of amphibian behavior by punishment*
}

\author{
M. SEGAL, M. HERSHKOWITZ, and DAVID SAMUEL \\ The Weizmann Institute of Science, Rehovot, Israel \\ and \\ M. E. BITTERMAN \\ University of South Florida, Tampa, Fla. 33620
}

Specimens of Pleurodeles waltl which were kept in deep water and shocked whenever they ascended to the surface for air soon ascended less frequently than yoked controls which were shocked independently of their own behavior whenever the experimental animals were shocked. The results suggest that, under suitable conditions, amphibians are capable of rapid learning.

It has been concluded from their sluggish and uneven performance in a variety of learning experiments that learning cannot have played a large part in the success of amphibians and that amphibians actually may be inferior to fishes in learning ability (Hempelmann, 1925; Noble, 1931; Warden, Jenkins, \& Warner, 1936; Thorpe, 1964). An alternative interpretation of the same results is that suitable conditions for the analysis of learning in amphibians were not employed (Van Bergeijk, 1967). Support for this view is provided by the fact that we have been able, at least in one urodele species, to produce rapid and reliable modification of behavior by the use of punishment. Our choice of punishment was based on an early study of the effect of shock on feeding in frogs (Schaeffer, 1911), but we decided to work with breathing rather than feeding because it is a more dependable response and easier to measure (Spurway \& Haldane, 1953).

Amphibians respire both through skin and lungs, the amount of gaseous exchange taking place at the different surfaces varying with species, stage of development, and environmental conditions (Foxon, 1964). In experiments with Triturus, for example, Spurway \& Haldane (1953) observed that the frequency with which specimens maintained in deep water would rise to the surface for air increased with temperature and decreased with the partial pressure of oxygen above the surface of the water. Finding ascent to the surface for air to be a stable pattern of behavior also in Pleurodeles waltl, we attempted to reduce its frequency of occurrence by

*This work was done while the last-named author was Visiting Professor in the Isotope Department of the Weizmann Institute. His participation was supported in part by Grant MH17736 from the United States Public Health Service. means of punishment with electric shock.

\section{METHOD}

The training apparatus was a 1-liter beaker into which two black perforated PVC plates, $10 \mathrm{~cm}$ wide, were placed. With the plates $2 \mathrm{~cm}$ apart and the beaker filled with water to the level of $12 \mathrm{~cm}$, the animal was confined to a space of $10 \times 2 \times 12 \mathrm{~cm}$ between the plates. Grids of stainless steel fixed behind the plates were used as shocking electrodes so that there was a fairly uniform flow of current across the animal's compartment when a voltage difference was applied. Ascent of the animal to the surface was detected with a photocell, a response being registered on a counter whenever the animal interrupted a beam of infrared light $1 \mathrm{~cm}$ below the level of the water.

About 1 month after metamorphosis, 40 naive animals were paired on the basis of size. The two members of each pair, side by side in identical beakers, were tested in a single experimental session. First, there was a 1-h period of adaptation to the apparatus, during the last $15 \mathrm{~min}$ of which the number of ascents made by each animal was recorded. In the next 2-h period, each ascent by one member of the pair, designated the experimental animal, was punished with 10-V shock. The shock was given in trains of five 0.2-sec pulses, with $0.8 \mathrm{sec}$ between pulses and $3 \mathrm{sec}$ between trains; it turned on automatically whenever the experimental animal ascended and turned off when the animal descended. The second member of each pair, serving as a yoked control, was shocked independently of its own location whenever the experimental animal was shocked because the two pairs of electrodes were connected in parallel. The number of ascents made by each animal in each 15-min interval of the 2-h training period was read from counters.

\section{RESULTS}

The results are plotted in Fig. 1 . In the first interval, which was the last portion of the adaptation period, the mean number of ascents made by the two groups was very much the same. At the beginning of training, there was some decrease in the number of ascents made by both groups, but the decrease was large and progressive in the experimental animals, while only small and transient in the controls. A nonparametric test for paired replicates based on total number of responses in the training period shows the difference between the two groups to be statistically significant at a level of confidence well beyond $1 \%$. Only 2 of the 20 experimental animals failed to make fewer ascents than their yoked controls.

The effectiveness of the instrumental contingency does not mean, of course, that we have here an instance of instrumental learning in the sense of a direct effect on the punished response. The measured change in behavior may be accounted for as well in terms of a classically conditioned aversion in the experimental animals to the upper region of the apparatus or to other stimuli correlated with ascent. Whichever interpretation is correct, the results do not lead us to suspect any learning deficiency in Pleurodeles, but encourage us to think further about the development of suitable techniques for the analysis of learning in this and other amphibian species.

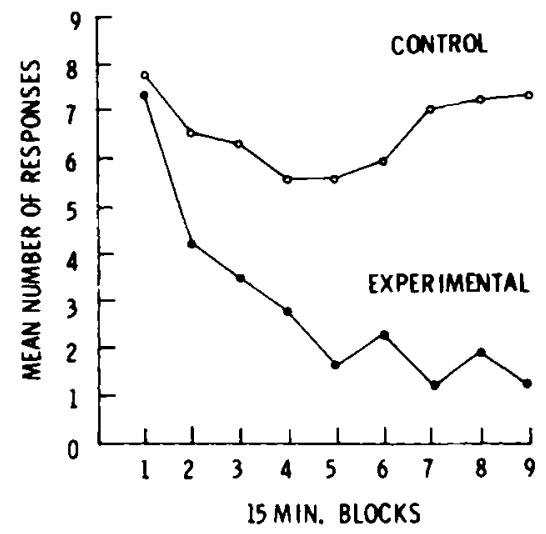

Fig. 1. Mean number of ascents to the surface made by the two groups in successive 15 -min intervals. In the first interval, no shock was given. In Intervals 2-9, both the experimental and the control animals of each pair were shocked whenever the experimental animal ascended.

\section{REFERENCES}

FOXON, G. E. H. Blood and respiration. In J. A. Moore (Ed.), Physiology of the amphibia. New York: Academic Press. 1964. Pp. 151-209. 
HEMPELMANN, F. Tierpsychologie vom Standpunkte des Biologen. Leipzig: Akademische Verlagsgesellschaft, 1925.

NOBLE, G. K. The biology of amphibia. New York: M cGraw-Hill, 1931 .

SCHAEFFER, A. A. Habit-formation in frogs. Journal of Animal Behavior, 1911
1, 309-335

SPURWAY, H., \& HALDANE, J. B. S. The comparative ethology of vertebrate breathing. 1. Breathing in newts, with a general survey. Behaviour, 1953, 6, 8-34. THORPE, $\mathrm{W} . \mathrm{H}$. Learning and instinct in animals. (2nd ed.) Cambridge: Harvard University Press, 1964.
VAN BERGEIJK, W. A. Anticipatory feeding and behaviour in the bullfrog (Rana catesbeiana). Animal Behaviour. $1967,15,231.238$

WARDEN, C. J.. JENKINS, T. N., \& W A R ER. L. N. Comparative psychology, Vol. 3, Vertebrates. New York: Ronald Press, 1936.

\section{CURRENT LITERATURE ON AVOIDANCE AND PUNISHMENT IN ANIMALS}

ASDOURIAN, D. (Wayne State University, Detroit, Mich. 48202), \& ANDREZIK, J. Cerebellar stimulation is effective as a CS at low stimulation intensities in rats. Journal of Comparative and Physiological Psychology, 1971, 75, 165-170.

B A L D E R R A M A, N , \& MALDONADO, H. (Centro de Biofísica y Bioquímica, Instituto Venezolano de Investigaciones Cientificas, Apartado 1827, Caracas, Venezuela). Habituation of the deimatic response in the mantid. Journal of Comparative and Physiological Psychology, 1971, 75, 98-106.

BINTZ, J. (University of California, Davis, Calif. 95616). Between- and within-subject effect of shock intensity on avoidance in goldfish (Carassius auratus). Journal of Comparative and Physiological Psychology, 1971, 75, 92-97.

BOE, E. E. (Graduate School of Education, University of Pennsylvania, Philadelphia, Pa. 19104). Variable Punishment. Journal of Comparative and Physiological Psychology, 1971, 75, 73-76.

EN T I NGH, D. (Neurobiology Curriculum, Department of Biochemistry, School of Medicine, University of North Carolina, Chapel Hill, N.C. 27514). Perseverative responding and hyperphagia following entorhinal lesions in cats. Journal of Comparative and Physiological
Psychology, 1971, 75, 50-58.

GALLUSCIO, E. H. (554 Gloria Drive, Baton Rouge, La. 70815 ). Retrograde amnesia induced by electroconvulsive shock and carbon dioxide anesthesia in rats: An attempt to stimulate recovery. Journal of Comparative and Physiological Psychology, 1971, 75, 136-140.

GERBEN, M. J. (U.S. Army Research Institute of Environmental Medicine, Natick, Mass. 01760), JONES, L. G., \& SMOAKE, J. A. Behavioral tolerance of squirrel monkeys to hypoxia: A model for evaluating drug therapy. Behavior Research Methods \& Instrumentation, 1971, 3, 10-12.

GLENDENNING, R. L., \& MEYER, D. R. (202 Kinnear Research Center, Ohio State University, Columbus, Ohio 43212). Motivationally related retroactive interference in discrimination learning by rats. Journal of Comparative and Physiological Psychology, 1971, 75, 153-156.

GORDON, A., \& BAUM, M. (Bishop's University, Lennoxville, Quebec, Canada). Increased efficacy of flooding (response prevention) in rats through positive intracranial stimulation. Journal of Comparative and Physiological Psychology, 1971, 75, 68-72.

HAWORTH, J. T. (University of Manchester, Manchester 13 , England). Conditioned emotional response phenomena and brain stimulation. British Journal of
Psychology, 1971, 62, 97-103.

JUSTESEN, D. R. (Veterans Administration Hospital, Kansas City, Mo. 64128), KING, N. W., \& CLARKE, R. L. Unavoidable gridshock without scrambling circuitry from a faradic source of low-radio-frequency current. Behavior Research Methods \& Instrumentation, 1971, 3, 131-135. KELSEY, J. E., \& GROSSMAN, S. P. (University of Chicago, Chicago, Ill. 60637 ). Nonperseverative disruption of behavioral inhibition following septal lesions in rats. Journal of Comparative and Physiological Psychology, 1971, 75, 302-311.

LEVIS, D. J. (University of Iowa, Iowa City, Iowa 52240 ). One-trial-a-day avoidance learning. Behavior Research Methods \& Instrumentation, 1971, 3, 65-67.

MANNING, F. J. (Department of Experimental Psychology, Walter Reed Army Institute of Research, Walter Reed Army Medical Center, Washington, D.C. 20012). Punishment for errors and visual-discrimination learning by monkeys with inferotemporal cortex lesions. Journal of Comparative and Physiological Psychology, 1971, 75, 146-152.

PORTER, J. J. (University of Wisconsin, Milwaukee, Wis. 53201), DAVIS, R. C., \& MADISON, H. L. Instrumental escape behavior with extended training. Behavior $\mathrm{R}$ ese a r h $\mathrm{M}$ e thods \& Instrumentation, 1971, 3, 127-129. 